\title{
ESCOLAS DO RIO DE JANEIRO OCUPADAS: NOVOS MOVIMENTOS SOCIAIS E A VONTADE COLETIVA ESTUDANTIL
}

\author{
Rafael Bastos ${ }^{1}$ \\ Viviane Marinho da Costa ${ }^{2}$
}

\begin{abstract}
Resumo
O objeto deste texto consiste na análise de ocupações de escolas públicas da rede básica de educação do estado do Rio de Janeiro. As metodologias utilizadas foram: observação participante em quatro escolas das regiões metropolitana do Rio de Janeiro e da serrana; análises das representações sociais dos discentes (obtida por meio de questionários, entrevistas e consulta a páginas em mídias sociais). Verificamos que as experiências políticas vividas, assim como o contexto contemporâneo de mobilizações sociais constantes (sobretudo por meio do uso de redes sociais), foram significativas para a construção da vontade coletiva dos sujeitos envolvidos nas ocupações. Apoiamo-nos no pensamento de Gramsci para discutir as possibilidades e contradições do debate complexo que estes Novos Movimentos Sociais brasileiros protagonizam. Esta investigação permitiu sistematizar um conjunto de categorias de conteúdo que expressam demandas contemporâneas, tais como as características da luta desses jovens por uma educação de qualidade, além do empoderamento feminino.
\end{abstract}

Palavras-chave: Ocupações Estudantis; Representações Sociais; Vontade Coletiva.

OCCUPIED SCHOOLS IN RIO DE JANEIRO: NEW SOCIAL MOVEMENTS AND THE COLLECTIVE WILL OF STUDENTS

\section{Abstract}

The purpose of this study is to analyze the occupation of a few public schools that integrate the basic education network of the state of Rio de Janeiro. The

\footnotetext{
${ }^{1}$ Doutor em Políticas Públicas e Formação Humana pela Universidade do Estado do Rio de Janeiro (UERJ). Professor adjunto na UERJ. E-mail: rafaelbastosoliveira@yahoo.com.br 2 Doutora em Alimentação, Nutrição e Saúde pela Universidade do Estado do Rio de Janeiro (UERJ). Professora da Universidade Federal do Rio de Janeiro (UFRJ). E-mail: vivianemarinhoc@gmail.com
} 
methodologies used in this research were: participant observation in four schools located in the Metropolitan and Mountain regions of Rio de Janeiro; and analyses of the social representations of students (obtained through questionnaires, interviews, and queries to social media pages). We verified that the political experiences and the contemporary context of constant social mobilizations (especially via social media) were significant for the construction of the collective will of the subjects involved in the occupations. We rely on Gramsci's thinking to discuss the possibilities and contradictions of the complex debate stirred up by these New Brazilian Social Movements. This investigation allowed us to create a set of content categories that portray latent contemporary demands, such as the characteristics of these young people's fight for quality education, in addition to female empowerment.

Keywords: Student Occupation; Social Representation; Collective Will.

\section{ESCUELAS DE RÍO DE JANEIRO OCUPADAS: NUEVOS MOVIMIENTOS SOCIALES Y VOLUNTAD COLECTIVA ESTUDIANTIL}

\section{Resumen}

El objeto del estudio es el análisis de las ocupaciones de las escuelas públicas de la red de educación básica del estado de Rio de Janeiro. Las metodologías utilizadas fueron: observación participante en cuatro escuelas de las regiones metropolitana de Rio de Janeiro y región de las montañas; análisis de las representaciones sociales de los estudiantes (obtenidas a través de cuestionarios, entrevistas y consultas en páginas de redes sociales). Comprobamos que las experiencias políticas vividas, así como el contexto contemporáneo de movilizaciones sociales constantes (sobre todo través del uso de redes sociales), fueron importantes para la construcción de la voluntad colectiva de los sujetos involucrados en las ocupaciones. Subvencionamos en el pensamiento de Gramsci para discutir las posibilidades y contradicciones del complejo debate que juegan estos nuevos movimientos sociales brasileños. Esta investigación permitió sistematizar un conjunto de categorías de contenido que expresan demandas contemporáneas, como las características de la lucha de estos jóvenes por una educación de calidad, además del empoderamiento femenino.

Palabras clave: Ocupaciones estudiantiles; Representaciones sociales; Voluntad colectiva.

\section{Introdução}

Este artigo tem como questão central analisar como a vontade coletiva empreendida pelos estudantes ocupantes de algumas escolas da rede básica de educação do estado do Rio de Janeiro, no ano de 2016, foi desenvolvida e se configurou, assim como são objeto de reflexão os principais fenômenos constatados. Para isso adotamos o legado de Antônio Gramsci para tecer a 
discussão analítica ${ }^{3}$. A respeito da própria categoria vontade coletiva, localizamos brevemente o pensamento gramsciano no campo da ciência política clássica. Ampliando a discussão teórica, trazemos à tona o debate contemporâneo sobre os chamados Novos Movimentos Sociais (GOHN, 1997; ALVES 2012; CARNEIRO, 2012; NOGUEIRA, 2013), uma vez que às ocupações de escolas investigadas se assemelham com formas contemporâneas de mobilizações coletivas realizadas em outros contextos, inclusive internacionais (a exemplo do vizinho Chile).

Sobre o campo empírico da pesquisa, levantamos as principais representações dos discentes - com base em Bourdieu (2011) - sobre o movimento que eles realizavam e também elencamos algumas categorias de conteúdo (KUENZER,1998) que consideramos fundamentais para a discussão dessas representações. Não pretendemos com esse escrito aprofundar as análises de todas as categorias, uma vez que isso vem sendo feito no conjunto da produção do conhecimento em elaboração, no entanto apresentamos as mesmas, ainda que mais brevemente, em alguns casos, como forma de materializar as construções da vontade coletiva empreendida por estes jovens. Às categorias mais relacionadas com o escopo teórico gramsciano, sobre a vontade coletiva, é foco do texto. Os pontos principais constatados nas pesquisas empíricas e que categorizamos são os seguintes 4 :

1. debates sobre feminismo e protagonismo feminino nas atividades de liderança; 2. diversidade sexual e respeito às minorias; 3. Autogestão; 4. questionamento do modelo de gestão escolar atual e luta pela gestão democrática; 5. revisão dos currículos escolares; 6. questionamento sobre a democracia contemporânea e seus limites para a juventude; 7 . crítica ao sistema político partidário vigente; 8. identificação com o espaço público; e 9. participação política.

\footnotetext{
3 A investigação faz parte de um conjunto de pesquisas que os autores deste texto desenvolvem, à medida que publicamos artigos anteriores, vamos ampliando às reflexões sobre a temática.

${ }^{4}$ A partir desta passagem do texto as categorias de conteúdo da pesquisa serão sinalizadas com negrito.
} 
Sobre à vontade coletiva dos discentes, às quatro últimas elencadas foram balizadoras para refletir sobre a construção do pensamento político dessa juventude. A dimensão da práxis gramsciana é mister para interpretar o fenômeno das ocupações, uma vez que ocorre um processo dialético entre mobilizar-se, lutar por direitos, promover a participação política, gerir a escola e pensar-se na condição de sujeito histórico social que faz parte de uma sociedade dada, contraditória e aspirar determinadas mudanças na hegemonia posta.

Sobre esta hegemonia, a teoria dos Novos Movimentos Sociais (GOHN, 1997), permite constatar que diversas formas atuais de lutas políticas são feitas por redes, de um modo descentralizado, sem lideranças (tal qual os movimentos sociais clássicos faziam), por vezes têm um forte teor crítico ao modus operandi do capitalismo global e da democracia representativa liberal, porém se deparam com enormes dificuldades de construir uma agenda de longa data das suas pautas. Passados três anos das ocupações brasileiras, essa tendência vem se verificando empiricamente. Outra tendência não incomum desses chamados novos movimentos sociais é tecer uma crítica que aponta para uma descrença sobre a lógica política atual.

Por outro lado, a mobilização destes estudantes provocou uma forte contestação no conformismo existente referente à qualidade da educação pública brasileira. 0 discurso prevalecente (feito por parte das frações de classe hegemônicas no Brasil ${ }^{5}$, reproduzidos largamente pela imprensa), indica que o problema da educação pública é a gestão, ou melhor, a má gestão dos recursos. Desta forma, bons dirigentes, que seguissem principalmente as premissas do mercado, trariam resultados satisfatórios para as metas educacionais, como descreve Paro (2016).

As ocupações estudantis contestam as condições sociais, históricas e políticas da educação do estado e do país (de certo modo), pois são feitas denúncias ligadas às questões estruturais da escola pública.

\footnotetext{
${ }^{5}$ Para maiores informações ver o Movimento Todos pela Educação (https://www.todospelaeducacao.org.br/), Fundação Lehamn (https://fundacaolemann.org.br/?gclid=EAIaIQobChMI7ZO8msOr4QIVEA6RCh2tDgdeEAAY ASAAEgI0CvD_BwE)
} 
Consequentemente, a vontade coletiva configurada vai na contramão do establishment posto, sendo assim, uma luta de hegemonia é travada.

Ampliando o entendimento sobre o conformismo vigente na área da educação, destacamos que há um privilégio da pequena política sobre a grande política ${ }^{6}$ no Brasil. De uma forma geral tanto a classe política, quanto a imprensa, não pautam os debates nevrálgicos sobre a educação (que compõem a grande política), por exemplo, a falta de um sistema nacional de educação, a protelação e descontinuidade com essa área, a desvalorização docente, o não diálogo com as identidades dos discentes, o não protagonismo dos estudantes nos processos políticos e pedagógicos da educação e principalmente como a educação é um elemento estratégico para o país na busca do enfrentamento da nossa condição de país dependente (TRASPADINI, 2018). Desse modo o trato quase que exclusivo sobre o problema da gestão está no campo da pequena política. Gramsci (2011) indica, que a elaboração do conformismo é orgânica, contraditória, não é estática e perpassa pela ação do Estado (assim como da sociedade civil), que usa do direito para tornar "homogêneo" o grupo dominante, construindo um conformismo que convém à classe dirigente. Essa tentativa de construção do conformismo também diz respeito à luta pela hegemonia da sociedade civil, uma vez que crises são constantes, pois velhos dirigentes intelectuais e morais veem seu discurso enfrentar resistência por parte dos dominados.

Esta formulação elucida exatamente a retórica dos agentes dos aparelhos privados de hegemonia e do Estado que ponderam que o problema da educação é de gestão e não precisa de mudanças estruturais profundas. Também, na ocasião das ocupações, no Rio de Janeiro e no país como um todo, diversos governadores e a própria mídia fizeram críticas e comentários desqualificantes sobre as manifestações estudantis, sem se preocupar em ouvir as pautas demandadas ${ }^{7}$.

\footnotetext{
6 Gramsci (2011) indica que a pequena política está voltada para questões cotidianas, parciais contidas em uma estrutura já estabelecida, no qual há uma predominância de frações de uma mesma classe política. Em contrapartida a grande política engloba a hegemonia em ampla escala.

7 Ver: http://g1.globo.com/rio-de-janeiro/noticia/2016/03/dornelles-diz-que-escolas-do-rj-naoserao-desocupadas-pela-pm.html Acesso em: 30 de Março de 2017.
} 
Com este texto, objetivamos ajudar a compreender o movimento de ocupação de escolas no Brasil, em suas dimensões históricas e políticas. Para tal, realizamos um breve apanhado sobre as ocupações estudantis brasileiras para contextualizar o cenário em que se inserem as ocupações ocorridas no Estado do Rio de Janeiro, alvo principal de nossa investigação.

0 texto está estruturado da seguinte forma, no primeiro tópico analítico, descrevemos a conjuntura em que ocorreu a ebulição das ocupações, em seguida pensamos teoricamente sobre as características destes novos movimentos sociais, analisamos a vontade coletiva mobilizada, tendo o prisma gramsciano como base teórica. A partir disso, ponderamos sobre às possibilidades da luta estudantil, problematizando a potência da luta estabelecida e às perspectivas de manutenção de uma agenda futura, que englobe tanto a defesa da educação, quanto a construção de uma perspectiva de cidadania política participativa etc. Em sintonia com a filosofia da práxis, os nexos entre a particularidade do movimento e à totalidade da luta política é traçada. 0 penúltimo tópico tem caráter mais descritivo e discorre sobre algumas categorias de conteúdo fundamentais da base empírica da pesquisa.

Nas conclusões apontamos que as ocupações foram experiências significativas para estes sujeitos, na perspectiva da construção da identidade coletiva, da participação política, do protagonismo jovem, que por meio de uma práxis de luta redimensionam sentidos na formação escolar e da vida social como um todo.

\section{A conjuntura em que se inserem nacionalmente e localmente as ocupações de escolas}

O presente estudo trata do fenômeno ocorrido no ano de 2016, nos meses de março a junho, quando da ocupação de dezenas de escolas da rede estadual de educação do Estado do Rio de Janeiro.

\footnotetext{
http://www.correiobraziliense.com.br/app/noticia/brasil/2016/05/06/internas_polbraeco,530740/ geraldo-alckmin-diz-que-ocupacoes-de-escolas-viraram-glamour.shtml Acesso em: 30 de março de 2017.

http://g1.globo.com/sao-paulo/sorocaba-jundiai/noticia/2016/04/alckmin-critica-ocupacao-emescola-estadual-em-sp-invasao-seletiva.html Acesso em: 30 de março de 2017. http://educacao.estadao.com.br/noticias/geral,voce-tira-o-direito-de-quem-quer-estudar-dizalckmin-sobre-ocupacoes, 10000086409 Acesso em: 30 de março de 2017.
} 
O movimento de ocupações de escolas no Brasil tem como marcos alguns fatos históricos que foram desencadeadores dessa tática de luta. Este fenômeno não é uma peculiaridade local, mas também pode ser verificado no contexto latino-americano ${ }^{8}$ e global $^{9}$.

As manifestações tiveram características comuns, como a descentralização, crítica à forma tradicional de manifestação no campo democrático popular (via partidos de esquerda e sindicatos), mobilização por redes. Assim, podem ser entendidas como uma típica ação dos Novos Movimentos Sociais (GOHN, 2017).

As Jornadas de junho de 2013, no Brasil, também ajudaram a construir um cenário de inquietação popular, luta por direitos e contestação de rumos da política.

Especificamente, no âmbito escolar brasileiro, podemos destacar o mês de setembro de 2015 como um importante momento para o acirramento das tensões sociais. Nesse período, em São Paulo, eram anunciadas medidas, por parte do governo do estado, que através de uma proposta denominada de reorganização escolar, sinalizava o fechamento de quase cem escolas. Além disso, o projeto apresentado traria impacto na vida de um milhão de alunos que seriam transferidos das suas respectivas unidades educacionais de origem para que as escolas passassem a atender exclusivamente um ciclo educacional (ensino fundamental I, ensino fundamental II e ensino médio). Essas medidas, completamente verticais e arbitrárias, não foram construídas com os setores interessados e diretamente impactados por elas, quais sejam, a comunidade escolar como um todo (CAMPOS, MEDEIROS e RIBEIRO, 2016).

Esse foi um dos fatores de estopim para o início das manifestações contra a chamada reorganização escolar. De acordo com Moraes e Ximenes (2016) a reorganização escolar veio à tona por meio de um processo altamente problemático, marcado pelas seguintes características:

(O governo de Geraldo Alckmin objetivava) transferir centenas de milhares de alunos entre escolas da rede pública estadual, mudar os ciclos atendidos em mais de 700 escolas e fechar quase uma centena delas. Esse era o denominado

\footnotetext{
${ }^{8}$ Vide caso dos estudantes chilenos, em 2006, conhecida como a revolta dos pinguins.

${ }^{9}$ Como os movimentos Occupy, nos EUA, Marcha Popular Indignada, na Espanha etc.
} 
programa de "Reorganização Escolar". Sem debate público transparente, sem consultas aos principais envolvidos - às escolas e seus professores e alunos -, sem diagnóstico prévio que fundamentasse a amplitude das mudanças pretendidas e sua alegada vinculação à melhoria da qualidade, 0 projeto propunha unilateralmente uma verdadeira megaoperação de reestruturação, com impacto na atividade profissional de milhares de professores e sem qualquer garantia do uso dos prédios públicos para outras atividades educacionais. Tudo isso quando o Estado deveria estar discutindo a regulamentação da gestão democrática em sua rede, conforme determina o art. 9o da Lei no 13.005/2015 - Plano Nacional de Educação (BRASIL, 2014). (...) Segundo a Administração, havia vagas ociosas nas escolas. Tal afirmação se baseava na alegada redução de cerca de 2 milhões de alunos, nos últimos 17 anos, na rede estadual. Argumentava, também, com fundamentação em estudo elaborado pela Coordenadoria de Informação, Monitoramento e Avaliação Educacional (Cima), órgão da Secretaria Estadual de Educação (SEE-SP), que "sob a ótica da aprendizagem" a separação por ciclos favoreceria o desempenho superior dos alunos. (MORAES; XIMENES. 2016, grifos nossos).

Posteriormente, argumentam os autores, uma análise do Programa de Pós-Graduação em Políticas Públicas da Universidade Federal do ABC se debruçou sobre os pressupostos do estudo feito pela Cima e foi constada uma ausência de rigor científico. Apontou-se que este se respaldava em uma variável única de desempenho (o número de ciclos existentes em cada escola). Todas as demais variáveis fundamentais para o estudo de desempenho e avaliação externa (como o índice socioeconômico dos estudantes, a situação dos professores, o número de alunos por sala, dentre outros) não foram considerados, (MORAES; XIMENES. 2016).

Como resposta a isso, diversas manifestações começaram a ganhar corpo nas ruas - entre setembro e novembro de 2015 - e que se voltaram posteriormente para os espaços escolares. As ocupações das escolas de São Paulo se iniciaram em 08 de novembro de 2015 e chegaram ao ápice no início do mês de dezembro quando mais de duzentas escolas encontravam-se ocupadas (CAMPOS, MEDEIROS e RIBEIRO, 2016).

Dados difundidos na grande mídia apontam que este fenômeno paulista inspirou diversos estudantes de outros estados a ocupar suas escolas também. A mobilização através de ocupações atingiu 19 estados e quase mil escolas em todo o Brasil, em outubro de 2016 (Globo, 2016; El País, 2016). Os estudantes ocupantes se mobilizavam reivindicando demandas locais, 
porém as ocupações tinham um caráter nacional também, pois era pautada, por exemplo, a contrariedade à Proposta de Emenda Constitucional 241/2016 10 - que versa sobre o congelamento dos gastos públicos em várias áreas, como saúde e educação, por vinte anos; e à Medida Provisória 746/2016 de reestruturação do ensino médio - que flexibiliza os currículos e, segundo diversos críticos à medida, pode ter como resultados o aprofundamento das desigualdades e o aumento da evasão escolar.

Além do posicionamento contrário a estas medidas, os manifestantes revelaram-se críticos às condições precárias de infraestrutura na educação básica brasileira (a alimentação escolar ruim, funcionários da educação desvalorizados e com pagamentos em atraso, descumprimento da constituição no que se refere ao financiamento da educação, falta de docentes, entre outras coisas), como revela um documento da União Brasileira dos Estudantes Secundaristas (2016).

Flach e Schlesener (2017) tomam como base para a análise de conjuntura o cenário nacional, durante o período de 2016 a 2017. Esse período foi palco de embates que repercutiram no objeto em questão deste artigo. Como um dos exemplos mais significativos temos a própria crise política brasileira, que se desdobra em uma crise econômica, das instituições e dos poderes políticos. Um dos auges dessa turbulência culminou no impeachment da ex-presidenta Dilma Rousseff. Até os dias atuais, esse episódio carece de respaldo político e jurídico que o justifique com algo razoavelmente aceitável.

As ocupações fluminenses podem ser localizadas também em um movimento de ataques a direitos sociais importantes da população brasileira como um todo.

Um grande marco disso foi a aprovação da emenda constitucional no 95/2016 (que praticamente congela os gastos das políticas sociais, assegurando os compromissos com a Lei de Responsabilidade Fiscal). Na

\footnotetext{
10 Posteriormente essa PEC foi aprovada e transformada na Emenda Constitucional 95/2016.
} 
educação isso tem fortes desdobramentos, pois inviabiliza ${ }^{11}$ a Meta $20^{12}$ do Plano Nacional de Educação (2014-2024).

Paralelamente à esta política de cunho econômico, mas de impacto societário, na educação, é aprovada a Lei 13.415/2017, da Reforma do Ensino Médio. Essa surge inicialmente via Medida Provisória (MP no 746/2016), até virar lei. Modifica-se assim parte da Lei de Diretrizes e Bases da Educação Nacional e reverbera na qualidade da educação das camadas que dependem da escola pública para estudar. 0 detalhe da proposta é que é feita sem o mínimo de debate com a população brasileira, nem com a academia e especialistas da área.

Motta e Frigotto (2017) ponderam que a Reforma do Ensino Médio tem uma relação com a PEC 55 e com o Projeto de Lei no 867/2015 (Escola sem Partido) e que este conjunto de medidas representa um retrocesso econômico, cultural, ético, político e filosófico da educação brasileira. Devido ao seu teor ela é feita com muita pressa.

Saviani (2014) entende que uma das características da educação no Brasil é a protelação e a descontinuidade. Esta reforma não rompe com a descontinuidade, mas não protela o andamento dos interesses contraditórios do então governo Temer (2016-2018).

A despeito destes argumentos, este governo propagandeou 13 nas mídias que o Novo Ensino Médio contou com a colaboração intensa de especialistas e tem aprovação de $72 \%$ da sociedade, de acordo com pesquisa do Instituto Brasileiro de Geografia e Estatística.

Flach e Schlesener (2017) discutem também as ocupações dos estudantes secundaristas do Paraná, feitas a partir de outubro de 2016. Estas lutas tiveram como uma das pautas centrais exatamente o combate à MP $746 / 2016$.

\footnotetext{
${ }^{11}$ Ver: https://danielcara.blogosfera.uol.com.br/2016/10/11/o-brasil-diminuiu-sob-o-teto-da-pec241/

${ }^{12}$ Que trata da destinação de $10 \%$ do Produto Interno Bruto para a área de educação até o ano de 2024.

${ }^{13} \mathrm{https://www.youtube.com/watch?v=iIszj0WWqfA}$
} 
Os casos brevemente aqui descritos de São Paulo e do Paraná, convergem com o movimento do Rio de Janeiro, compondo uma contestação da hegemonia da pequena política.

Fica evidente como a luta por uma educação de qualidade, o inconformismo com a hegemonia política brasileira atual e a resistência da sociedade política expressam uma crise de hegemonia, de forma a escancarar os limites da conformação do arranjo do Estado ampliado brasileiro vigente. 0 que queremos dizer é que o velho e o novo convivem dialeticamente na atualidade. Por um âmbito, a velha política mantém a sua linha de atuação hegemônica (tipicamente na perspectiva da via prussiana) e por outro, novos movimentos, com sociabilidades muito próprias pedem passagem, colocando o conflito classista na pauta do dia. Este último movimento forja uma vontade coletiva importante e que merece ser compreendida.

Sob o lema "Ocupar e Resistir", os jovens estudantes mobilizaram uma vontade coletiva altamente insubordinada, contestatória e progressista, o que vai ao encontro do espírito jacobino ${ }^{14}$ fundamental propagado por Gramsci (2011).

Cabe aqui apontar também os contornos locais das problemáticas vividas pela educação básica. 0 movimento de ocupações no Rio de Janeiro surge em uma conjuntura de crise política e econômica a nível nacional, assim como também se insere no contexto de grave crise financeira da gestão pública do estado do Rio de Janeiro, que culminou com o decreto de calamidade pública por parte do governador em exercício Francisco Dorneles (Decreto 45.692/16).

Pontuamos alguns fatos relevantes que impulsionaram o crescimento do movimento localmente, como: atrasos no pagamento dos servidores estaduais; a divulgação do pacote de maldades - como se convencionou chamar o pacote de medidas que atacavam os direitos dos servidores

\footnotetext{
${ }_{14}$ Para este autor, o jacobinismo era dotado de aspectos contraditórios da luta burguesa, na França, contudo, era provido de grande capacidade enérgica de mobilização e mudança rumo a um novo tipo de Estado. Os estudantes investigados não reivindicavam categoricamente um novo tipo de Estado, porém havia uma predominância crítica ao modos operandi da política moderna.
} 
proposto pelo governador Luiz Fernando Pezão para sanar a crise financeira do Estado; a possibilidade de votação na câmara dos deputados do Projeto de Lei 867/14 (SEPE, 2015, 2016a, 2016b, 2016c). Em reação a esse contexto, diversas categorias fizeram greves e manifestações, entre estes os profissionais da rede estadual de educação básica.

O objeto de estudo aqui apresentado trata de algumas experiências das ocupações de escolas públicas estaduais, da rede básica de educação do estado do Rio de Janeiro. Durante aproximadamente quatro meses - entre os meses de março e junho - os estudantes da rede iniciaram um processo de ocupações das escolas com objetivo de reivindicar inúmeras demandas, engrossando o coro das pautas dos profissionais de educação, incluindo propostas construídas pelas organizações estudantis, como também incorporando pautas de cada unidade escolar em particular.

Diante das medidas do governo do estado, que visavam coibir a greve da educação (ameaçando cortar os salários dos funcionários grevistas), a mobilização estudantil, pela via das ocupações dos espaços escolares, se configurou como uma tática central para a legitimação e continuidade da greve e da luta geral na educação.

Esta descrição da conjuntura demonstra que dialeticamente os fenômenos locais (particulares) estão estreitamente relacionados às mediações mais globais (totais). Verificamos que os chamados Novos Movimentos Sociais, produzem um tipo de ação política que mantém uma regularidade na sua materialização em várias partes do mundo. Compreendemos que estas ações resultam em uma vontade coletiva que se demonstra contrária às estruturas políticas e de poder, em geral, colocadas. Desta forma, há uma tentativa de produzir novas sínteses (modos de organização política, que projeto de sociedade pautar e etc.) que ainda não estão muito elucidadas. Contudo, as pautas específicas desses movimentos impulsionam de forma veemente uma energia fundamental para proporcionar mudanças no status quo.

A respectiva formulação de Marx nos ajuda a entender um pouco desse processo. 
Uma sociedade jamais desaparece antes que estejam desenvolvidas todas as forças produtivas que possa conter, e as relações de produção novas e superiores não tomam jamais seu lugar antes que as condições materiais de existência dessas relações tenham sido incubadas no próprio seio da velha sociedade. Eis porque a humanidade não se propõe nunca senão os problemas que ela pode resolver, pois, aprofundando a análise, ver-se-á sempre que o próprio problema só se apresenta quando as condições materiais para o resolver existem ou estão em vias de existir. (MARX, 2008, p.48)

As ocupações refletem, sem dúvidas, uma vontade coletiva contrária aos problemas políticos, sociais e econômicos nevrálgicos do Brasil atual, reproduzem formas dos Novos Movimentos Sociais mundiais e apresenta dificuldades semelhantes a estas manifestações.

Como descreve Ellen Wood (2011), no contexto de avanço da mercantilização da vida, a luta por democracia (social, econômica e política) acirra os confrontos de classe da sociabilidade contemporânea.

A conjuntura atual no mundo é de diminuição de direitos, como descreve Piketty (2014) e a resistência global se mobiliza em um sentido contrário a isto. Portanto estamos diante de um fenômeno importantíssimo.

A crise política brasileira tem nuances tão sui generis e complexas que além dos movimentos de resistência e dos embates destes com a velha política, testemunhamos a ação de Novíssimos Movimentos Sociais (GOHN, 2017), dentre eles, alguns de cunho muito conservador, tais como o Movimento Brasil Livre (MBL) e Vem Pra Rua (VPR).

Em uma grande catarse, sujeitos que posteriormente vieram a compor as ocupações de escolas e estes movimentos novíssimos estiveram nas ruas do país nas Jornadas de Junho de 2013. Contudo, as vontades coletivas desenhadas a partir de 2014, tomaram rumos bem distintos.

Os estudantes secundaristas ocupantes, expressam um espírito tipicamente jacobino, enquanto o MBL e o VPR aderem a uma pauta 
conservadora e de direita. Paradoxalmente, ambos utilizaram formas de luta um tanto quanto parecidas com as dos Novos Movimentos Sociais.

Esse cenário é contraditório, complexo e cheio de nuances, como é o debate sobre os Novos Movimentos Sociais. Contudo, focamos na particularidade discente. Apenas trouxemos à tona as respectivas mediações como mais uma forma de localizar o objeto.

\section{Novos Movimentos Sociais e a vontade coletiva em questão}

Ao discutir as teorias dos movimentos sociais, Gohn (1997) descreve que o paradigma dos Novos Movimentos Sociais (NMS) mobiliza explicações que partem de aspectos conjunturais, envolve microprocessos da vida cotidiana e tem como categorias básicas cultura, identidade, autonomia, subjetividade, interação política, cotidiano, representações etc. Segundo a autora este paradigma tem forte influência da interpretação pósestruturalista e pós-moderna da cultura e seria uma crítica ou discordância do paradigma marxista denominado de ortodoxo.

As análises sobre os movimentos sociais no Brasil estão pautadas em duas vertentes de discussões, quais sejam: uma primeira, voltada para descrição de casos empíricos e outra, menos frequente, que se dedica a análise teórica dos paradigmas dos Movimentos Sociais (GOHN, 1997). Este estudo se aproxima da primeira perspectiva citada, pois buscamos entender as manifestações destes fenômenos recentes do século XXI. O respaldo teórico dado por Gohn é pertinente neste estudo, pois localizamos no trabalho de campo pontos de convergência com o paradigma dos Novos Movimentos Sociais.

Para Santos (2005) os Novos Movimentos Sociais articulam pautas globais e locais, além de promover, por vezes, tensões no que diz respeito ao debate sobre cidadania e subjetividade. Para ele estes movimentos revelam uma demanda de reivindicação de contemplação de aspectos subjetivos individuais meramente. Em outro polo, não é possível descartar que existe uma luta também por cidadania e direitos. Entendemos que o objeto deste 
texto é mais diretamente voltado para pautas de cidadania, porém sem desprezar os aspectos subjetivos.

Sobre a relação global e local, as ocupações das escolas da rede estadual do Rio de Janeiro têm semelhanças com as rebeliões e ocupações de 2011 e 2013. 0 ano de 2011 foi um marco importante internacionalmente, pois englobou desde as ocupações na Europa (na praça do sol, na Espanha, por exemplo) e até os Estados Unidos da América (com o movimento Occupy Wall Street).

Em 2013, o Brasil, desta vez, foi palco de movimentos parecidos, as chamadas Jornadas de Junho. Na ocasião, cidades do país inteiro registram milhares de pessoas nas ruas simultaneamente com as pautas das mais diversas possíveis - a exemplo: do fim da corrupção, até a posição contrária a Proposta de Emenda Constitucional 37/201115.

Estes movimentos têm diversas características em comum, desde o uso das redes sociais para se organizar, a capacidade de dar visibilidade aos seus atos, até o caráter um tanto quanto descentralizado e espontâneo, pois não têm uma liderança, nem seguem uma cartilha mais classista de mobilização, como o próprio Gramsci discutia (via partidos, aparelhos privados de hegemonia, sindicatos etc.).

Carneiro (2012) entende que o ano de 2011 tinha como pano de fundo uma crise social, econômica e financeira muito grande, se desdobrando na ação dos movimentos que contestavam as lideranças sindicais vigentes e contra as estruturas político partidárias (de direita ou de esquerda), mas sem forjar uma proposta de ruptura ou que construísse uma agenda de transformação à curto, médio ou longo prazo. Contudo, na África, ocorreram movimentos de cunho revolucionários que derrubaram ditaduras de décadas. Na Espanha e Grécia também foram construídas alternativas políticas contra-hegemônicas.

\footnotetext{
${ }^{15}$ A PEC propunha que fosse incluído um novo parágrafo na Constituição Federal no qual a tarefa de investigação de infrações penais seria da alçada exclusiva da Polícia Federal e civis dos estados.
} 
Já Nogueira (2013) analisa que o ano de 2013 revelou ao Brasil uma crise profunda de representatividade e de legitimidade. Algo que estava silenciado na sociedade civil local, "de repente" se apresenta "espontaneamente" e intensamente com uma grande força e potência contestadora.

Como já citamos anteriormente, as ocupações nas escolas no estado do Rio de Janeiro, de certo modo, seguiram esta tendência, pois foram oriundas de uma grave crise (tanto política, quanto econômica) do estado, que repercutiu em categorias tradicionalmente organizadas, como os educadores, que fizeram greve e diversos protestos, mas que também se desdobrou em atos protagonizados por jovens estudantes secundaristas.

Os discentes se solidarizaram com o movimento grevista dos educadores e construíram também sua pauta própria, marcando especificidades que demandam uma reflexão, pois revelam o gene da nova sociabilidade que emerge e que precisa ser entendida com as lentes do seu tempo e não necessariamente e somente com as do passado.

A ocupação dos estudantes do Rio de Janeiro também não teve lideranças claramente estabelecidas e pareceu com os movimentos globais vistos. Alves (2012) aponta que os movimentos sociais (como o Movimento dos Trabalhadores Rurais Sem Terra, os Zapatistas etc.) há tempos já adotavam a prática de ocupação como forma de resistência e luta pelas suas reivindicações. Os novos movimentos sociais também usam dessa tática, porém o autor questiona se esses movimentos terão força suficiente para construir uma agenda de longo prazo, capaz de construir outra hegemonia social e cultural, que trave uma guerra de posição contra a barbárie social e o capitalismo manipulatório que impera nesse momento.

Compartilhamos dessa indagação de Alves e na busca por entender esses movimentos, analisamos as características que consideramos centrais no objeto em questão. É exatamente nesse sentido que compreendemos que o legado gramsciano ajuda o entendimento do fenômeno e na sua dimensão da práxis social pode auxiliar na transformação da realidade concreta. 
Até então às experiências europeia, norte americana e a brasileira, não permitem apontar uma grande relação entre uma agenda de luta atual e o legado das ações de massas descritas no texto. Contudo, dialeticamente, diversos militantes e ativistas que participaram deste processo atuam na luta política contemporânea.

Desta forma, ampliar estudos que articulem a vontade coletiva dessas lutas com a arena de conflitos atuais é uma tarefa desafiadora, importante e necessária. Este artigo se propõe a fazer isso no âmbito educacional, dentro de uma conjuntura regional.

Coutinho (2017, p.812) destaca que Gramsci define a vontade coletiva como algo fundamental que movimenta o ser humano e materializa possibilidades de mudanças na ordem social, econômica e política. Contudo, o autor realça que esta vontade teleológica emerge das relações concretas, não de modo espontâneo, e na relação de práxis se forja. Verificamos isso empiricamente, nas atividades de ida à campo, pois os jovens encontraram na própria ação direta um sentido de construção de subjetividade, consciência de classe e de possibilidade de mudanças, que é exatamente a práxis humana em movimento.

Esse objeto é imbuído de especificidades históricas, no qual precisamos mobilizar pensadores contemporâneos, como Gohn $(1997,2017)$ e Nogueira (2013), para apreender algumas categorias do tempo presente. Novamente retornamos à Gramsci para fazer uma tentativa de síntese dialética que dê conta das contradições do objeto, da historicidade, particularidade, mediações e totalidade.

Nessa investigação lançamos mão de técnicas de pesquisa qualitativa como a observação participante, a aplicação de questionário auto preenchível com questões fechadas e abertas, a realização de entrevista semi-estruturada com lideranças-chave ${ }^{16}$ e de a pesquisa virtual em páginas de coletivos em mídias sociais.

16 Em todas entrevistas e na aplicação do questionário, o devido cuidado ético foi preservado. Utilizamos o TCLE antes de cada interpelação com os sujeitos da pesquisa. 
A observação participante foi realizada no período entre abril e maio de 2016 em quatro escolas estaduais. As visitas foram realizadas em dias e períodos distintos, tendo algumas escolas recebido mais de uma visita ${ }^{17}$. As escolas foram selecionadas com objetivo de obter uma maior variedade no perfil dos estudantes, assim como ampliar a compreensão das diferenças entre as regiões do estado. As escolas visitadas estão distribuídas geograficamente da seguinte forma: uma escola na Região Serrana; uma Escola na Baixada Fluminense; duas escolas na cidade do Rio de Janeiro.

Com os questionários aplicados tínhamos o intuito de verificar o papel do estudante na escola, o significado das ocupações para eles, e seu conhecimento sobre a proposta constitucional de gestão democrática da educação, prevista também na Lei de Diretrizes e Bases da Educação Nacional (Lei 9.394/96). Indagamos sobre sua participação nos espaços de gestão democrática da escola e buscamos apreender suas representações sociais sobre política e participação, assim como seus planos após a conclusão dos estudos na escola.

Realizamos algumas entrevistas com lideranças e/ou alunos que se dispuseram e que identificamos como informantes-chave para essa pesquisa. A seleção dos sujeitos entrevistados foi feita com base na observação dos pesquisadores em campo, no qual tentamos entender os papéis desempenhados pelos diversos jovens participantes da ocupação. Também contemplamos os discentes que tinham interesse em relatar suas experiências como protagonistas do processo em curso. Amparados pelas falas dos entrevistados foi possível realizar diversas sínteses, sobretudo, no que se refere aos desdobramentos da vontade coletiva instituída e do anseio de construção de uma gestão democrática na escola e de melhorias na educação.

\footnotetext{
${ }^{17}$ Em algumas escolas, retornamos mais de uma vez, como uma unidade localizada na zona norte do Rio de Janeiro, pois lá encontramos especificidades que nos instigou a melhor compreender o processo. Verificamos pais de alunos que também estavam ocupando. Neste local também à comunidade "abraçou" a causa, doando alimentos etc. Na região serrana, chamou atenção o fato de uma parte importante docentes se engajarem, de forma solidária, na luta estudantil.
} 
A pesquisa em mídias sociais foi feita com base em materiais levantados na rede social Facebook, em páginas relacionadas com a militância de estudantes do estado do Rio de Janeiro. Entre as páginas investigadas estão incluídas páginas de escolas ocupadas, páginas de coletivos de organização das ocupações e outras similares. As principais páginas lidas foram: a) Escolas do RJ em luta - página que se coloca como ponto de apoio para organização de novas ocupações de escolas, que centraliza divulgação de mobilizações e publica cartilhas para estudantes que objetivam se organizar.; b) Comando Ocupa Tudo; c) Secundaristas do RJ em luta; além de informações de outras páginas replicadas por essas páginas, perfis e comunidades.

Pensando no legado gramsciano, ao tratar da espontaneidade das classes subalternas, o autor enxerga um potencial de construção de uma consciência da "classe para si", (GRAMSCI, 2011, p. 194). É um desafio sociológico e político historicizar as categorias mobilizadas por este pensador para entender as manifestações dos confrontos vigentes.

Ampliando a discussão teórica deste texto, Gramsci (2014) destaca que Maquiavel, de um modo assertivo, ponderou, na sua análise do campo da ciência política, que à vontade coletiva é fruto de aspectos históricos, econômicos e de classe. 0 caráter do pensamento de Maquiavel, no século XVI, era de atribuir à figura do Príncipe a vontade coletiva nacional, sendo que não havia naquela ocasião um príncipe com esta característica no que hoje conhecemos como território italiano. De qualquer modo, Gramsci entendia que Maquiavel mobilizava categorias de análise fundamentais para entender o processo de construção da vontade coletiva.

Gramsci entende que, na modernidade, a vontade coletiva deve possuir uma dimensão jacobina, promovendo uma reforma intelectual, moral, além de mudanças no padrão econômico de vida. Ele se apropria de Maquiavel, constrói uma nova síntese e entende que o moderno príncipe, organizador da vontade coletiva, é o partido político, pois uma pessoa não pode ocupar esse papel, mas sim um organismo vivo ou um elemento social historicamente construído, consolidado e com perspectivas civilizatórias teleologicamente 
voltadas para o desenvolvimento das premissas aqui citadas. Por meio do partido, no século XX, pondera Gramsci (2014, p.375), as vontades coletivas parciais tendem a se tornar universais e totais.

Como já foi descrito, as ocupações de escolas podem ser analisadas pelo prisma dos novos movimentos sociais, que não mais organizam a sua vontade coletiva em torno de um partido, sindicato ou entidade clássica, como os movimentos dos anos 1970-1980 faziam. Estamos diante de um novo tipo de mobilização que faz sentido em coletividade, porém a forma de representação política e construção de significados é sui generis.

Gramsci (2004) também entende que o exercício da filosofia é um instrumento fundamental na passagem do entendimento do senso comum (o que inclui elementos típicos do dia a dia), para se chegar a um bom senso, ou uma noção culturalmente ampliada da consciência de classe. Esta investigação primordial levanta indagações que instigam análises futuras, tais como: saber os desdobramentos futuros no que se trata da vida política desses jovens e quais são às representações sociais que os mesmos têm sobre a política, a participação e à mobilização de vontades coletivas. Uma indagação latente também é saber como às lideranças da ocasião se organizam ou não nos dias atuais.

A literatura gramsciana possui semelhanças com alguns fundamentos de Rousseau, neste autor encontramos subsídios para entender que os estudantes, no espaço interno das ocupações, tinham uma preocupação bastante elevada entre a preservação da diversidade das identidades (étnicas, de gênero, sexuais etc.) e a garantia das tarefas coletivas ou efetivação da vontade geral. Isto foi crucial para a longevidade de desenvolvimento do sentimento de pertencimento dos estudantes nas escolas ocupadas, embora fosse aspecto de constantes tensões.

Mais do que uma busca rousseauniana por uma justiça coletiva, por meio de um contrato social, ou a partir da busca por uma ética, os discentes ocupantes, talvez mobilizassem mais um aspecto destacado por Gramsci (2011) que são as paixões políticas. 
Podemos verificar um senso de justiça (social) ao analisar as pautas do movimento, dentre elas, talvez a principal, uma educação pública de qualidade para eles e para às futuras gerações.

Por vezes, ao entrevistarmos os alunos, eles destacavam que não estavam preocupados com o vestibular deles naquele ano (2016), pois todos os anos têm este tipo de seleção, mas queriam mudar a educação hoje e deixar um legado para o futuro (fala constantemente presente nas entrevistas).

Este senso de vontade coletiva converge com a perspectiva pauta por Gramsci, descrita por Coutinho $(2009$, p.36), que entende que a vontade envolve, em última instância, a atividade política, prática, ou uma práxis política. Esta prática é feita pelo sujeito, podendo desenvolver no mesmo uma formação de consciência de classe - coletiva. Esta dinâmica caracterizaria a passagem para uma consciência classista, que extrapola os limites da individualidade.

Gramsci (2011, p.288) caracteriza a vontade coletiva como uma ação coletiva, no qual os sujeitos agem de forma coordenada e simultânea. Nesta práxis são construídos objetivos imediatos e concretos, que tem processos, em geral, longos. Raramente os fenômenos de vontade coletiva são explosões "sintéticas" inesperadas. Entendemos por isso, que as ditas explosões "sintéticas" são fruto também de acúmulos históricos, que levam a uma manifestação de vontade coletiva. Ou seja, existe então a interpelação de uma experiência histórica acumulada. Os objetivos imediatos dos estudantes foram dar visibilidade e batalhar pelas reivindicações de conseguir melhores condições para a educação no estado e melhorias na escola também. A adoção da tática de ocupação foi o caminho encontrado para concretizar a mobilização pelas reivindicações.

A vontade desses discentes foi sendo construída desde o debate posto nacionalmente por melhores condições para a educação (vide casos de SP e PR), perpassou, no nosso entendimento, pela conjuntura internacional (os casos dos occupy) e culminou localmente nas assembleias preparatórias nas escolas, se desenvolvendo no próprio espaço escolar, a partir da experiência da ocupação. 
0 autor pondera que é dificílimo analisar todo processo molecular, em escala mínima, capilar. Verificamos uma convergência com a respectiva afirmação durante a pesquisa e agora na análise. Nossos apontamentos se tornam ainda mais complexos, uma vez que as ocupações dos discentes guardam características próprias do século XXI (no qual a descentralização e "espontaneidade" são algumas das marcas), embora não neguem um legado histórico secular já feito pelos trabalhadores no mundo afora. Estas dimensões é que tomamos como base para discutir esse texto. É igualmente complexo, para Gramsci (2011, p.17), dizer ou compreender em que momento se configura uma vontade coletiva nacional-popular ${ }^{18}$.

Mesmo diante da forte característica da sociedade contemporânea, em rede e de certo modo dispersa (Castells, 2002 e Giddens, 1991), os discentes ocupantes, encontraram unidade (homogeneidade, Gramsci, 2011) em pontos (dentro de um campo, o educacional ${ }^{19}$ ) que entendemos que são elementos que envolvem uma mediação dialética entre a totalidade e a particularidade. A passagem de Coutinho (2009) ajuda a situar o debate:

Só "em alguns aspectos" a vontade coletiva é "criação ex-novo", já que ela é também, e ao mesmo tempo, "consciência operosa da 'necessidade' histórica." Temos aqui a articulação dialética entre teleologia e causalidade, entre os momentos subjetivos e objetivos da práxis humana, da qual a vontade é momento ineliminável. A vontade coletiva que se torna "protagonista de um real e efetivo drama histórico" - ou seja, que se torna um momento ontologicamente constitutivo da realidade social - é aquela marcada por esta dupla determinação. É precisamente aqui onde me parece que Gramsci supera dialeticamente - no sentido de conservar, mas também de levar a um patamar superior - a concepção de vontade geral ou universal tanto de Rousseau quanto de Hegel. Não posso demonstrar "aqui" - mas seria fácil fazê-lo - que esta superação nasce a partir da assimilação gramsciana do legado de Marx. (COUTINHO, 2009, p.36).

Gramsci aborda ainda que a reforma intelectual moral de uma sociedade, perpassa por um programa de reformas econômicas. Logo, pensar

\footnotetext{
${ }^{18}$ Apesar do autor se referir a outro contexto sócio-histórico, podemos fazer uma analogia com o objeto aqui investigado, pois o respectivo estudo de caso, tem dimensões nacionais também.

${ }^{19} \mathrm{~A}$ teoria dos campos supracitada é oriunda de Bourdieu (2001).
} 
uma condição melhor para a educação do país, como os estudantes fizeram, caracteriza uma rota de colisão com a agenda política vigente no país ${ }^{20}$.

Não à toa, diversas frações da classe dominante se mobilizam cada vez mais para formar um consenso e construir ideias sobre como deve ser o rumo da política pública de educação no país. São crescentes os chamados think tanks $^{21}$ que dedicam esforços para propor uma agenda para a educação. Mesmo grupos empresariais que concebem a educação como uma mercadoria, não deixam de pautar políticas públicas em educação, seja por meio ou não do Estado (Freitas, 2012). 0 conceito de aparelhos de hegemonia nos auxilia a entender o papel deste tipo de instituição contemporânea.

Os estudantes ocupantes apresentam a síntese de uma vontade coletiva que envolve a dimensão do Estado ampliado, com caráter classista, contra hegemônico e contestatório, que tem potencial de construir uma agenda política, que mexe nos pilares econômicos e é distinta do modus operandi atual no Brasil. Talvez aqui exista elementos importantes da construção de uma nova hegemonia.

Ainda não sabemos se os rumos desses movimentos desencadearão numa perspectiva do que Gramsci denomina de plano superior (da grande política), se as lutas se esgotarão na experiência vivida ou até mesmo se recairão numa apropriação burguesa.

Relacionando mais diretamente este debate com a pesquisa de campo, entendemos que algumas categorias de conteúdo encontradas na pesquisa empírica ajudam a formulação de hipóteses que estabelecem um vínculo entre as manifestações feitas, a construção de uma vontade coletiva e a disputa no plano superior (da grande política). As categorias referidas são as: questionamento sobre a democracia contemporânea e seus limites

\footnotetext{
${ }^{20} \mathrm{Na}$ ocasião, a agenda sobre a educação era marcada por contradições próprias das gestões dos governos do Partido dos Trabalhadores, na esfera Federal, como Freitas (2012) descreve. Contudo, apesar das contradições, a lógica financeira nunca deixou de ser hegemônica. 0 cenário que se desenhava (com a consolidação do impeachment de Dilma) apontava para uma piora desta tendência de desprestígio de políticas sociais. Hoje essa situação de fato se agravou com o governo Bolsonaro.

${ }^{21}$ Talvez um dos exemplos mais significantes da atualidade seja o Instituto Millenium.
} 
para a juventude; crítica ao sistema político partidário vigente; e participação política,

Sobre estes últimos aspectos, dedicamos maior atenção neste tópico do texto, pois entendemos que este é o viés teórico principal do artigo. Os estudantes manifestaram (sobretudo nas escolas da capital fluminense) resistência elevada tanto aos partidos políticos, quanto a entidades da categoria, como a União Brasileira dos Estudantes Secundaristas (UBES).

Interpretamos algumas questões ideológicas e utópicas desse fenômeno à luz de Gramsci. Ele descreve que ideologias confusas são comuns na construção da homogeneidade da vontade coletiva. De modo que os processos contraditórios da ideologia que se apresenta inicialmente vão sendo superados e subordinados por um núcleo de um novo processo ideológico e doutrinário (GRAMSCI, 2011). Para o autor, depois da formação do regime dos partidos, que é uma fase histórica ligada à estandardização de grandes massas da população, os processos moleculares se manifestam com mais rapidez do que no passado.

Como Gohn (1997), Carneiro (2012) e Alves (2012) apontaram, são características das manifestações contemporâneas a resistência à aproximação dos partidos nas fileiras dessas lutas. Gramsci (2011) entende que no espaço político as construções espontâneas, livres (arbítrio-impulso vital) ou idealistas têm uma materialidade absoluta. Desta forma, faz-se necessário entender todo o contexto de discussão sobre a pós-modernidade que Alves (2012), Harvey (2009), dentre outros, levantam para pensar se os Novos Movimentos Sociais são genuinamente espontâneos ou fruto da materialidade da sociabilidade pós-moderna, com seu caráter pulverizador das lutas sociais.

Dessa forma, podemos levantar algumas indagações. A primeira seria: a rechaça aos partidos pode fazer parte de um processo histórico de subordinação de ideologias difusas por uma nova síntese dialética que incorpore às tradicionais formas de luta históricas, o que inclui os partidos?; ou seriam essas lutas uma representação efetiva de novas formas de manifestação de massas, ainda sem precedentes à longo prazo? 
Consideramos estas questões antagônicas difíceis de responder em curto prazo.

Verificamos empiricamente, ao seguir acompanhando alguns manifestantes, nas redes sociais, após as ocupações findarem, que há uma politização nos debates oriundos desta experiência ${ }^{22}$.

Outros discentes, inclusive, já faziam parte de partidos ou demais organizações e não abriram mão desses instrumentos.

A respeito da identificação com a participação política os estudantes participantes das ocupações visitadas, em sua maioria com nenhuma experiência pregressa de organização e participação política, se mostraram muito identificados a militância. Foi muito comum perceber na fala dos mesmos uma identificação com a luta coletiva, com a construção democrática dos processos e de uma continuidade na atuação, compreendendo que a ocupação não se encerra em si mesma. A minoria já participou de grêmio estudantil ou até mesmo dos conselhos de classe da escola.

Em muitas escolas ocupadas pudemos verificar a criação ou reativação de grêmios estudantis; a construção de espaços coletivos deliberativos como assembleias gerais; a efetiva participação do estudante nos espaços deliberativos da escola. Falas como a de Lucas $^{23}$ apontam que a participação política é importante, pois segundo ele: "Eu percebi que minha opinião sim é importante para poder mudar a sociedade e os locais em que vivemos". Sobre o mesmo assunto Fernando diz: "eu aprendi que 'a união faz a força', nós jovens juntos podemos mudar o ensino e até mais coisas". Novamente o paradoxo já descrito anteriormente se revela no questionário de Fernando, pois ele afirmou que não se interessa por política.

Simone não respondeu o que entendia sobre a política, mas a respeito da pergunta sobre a participação ponderou: "aprendi que as mudanças acontecem com a participação política".

22 Muitos discentes apontaram que foi nas ocupações que de forma pioneira eles passaram a debater e ter mais atenção à atividade política.

23 Por motivos éticos demos nomes fictícios aos discentes aqui nesse texto. 
Gramsci (2011) entende que a participação é um aspecto importante, configurando um primeiro momento no qual a superestrutura está numa fase imediata, como mera afirmação voluntária, podendo configurar uma paixão ${ }^{24}$. Todavia, a política deve perpassar pelo patamar também estrutural (econômico) para se alcançar uma dimensão ponderada, racional, culminando então em um debate que pode levar a processos fundamentais como guerra de manobra ou de posição. Sem dúvidas, a construção de uma nova hegemonia perpassa por isto.

Esta reflexão do autor reforça a construção de uma das indagações que fizemos anteriormente para tentar entender esses Novos Movimentos Sociais e problematizar suas possibilidades futuras. Ou seja, as respectivas ocupações podem ser parte da construção política dos discentes, que ao desenvolverem uma consciência política, podem expandir a sua alçada de atuação política num futuro breve, médio ou longo prazo.

É possível também fazer um paralelo com a formulação de Gramsci sobre a construção política e filosófica da passagem de um pensamento de senso comum para a formação de um bom senso. A partir do senso comum, há uma apropriação da reflexão sobre o cotidiano e as questões mais imediatas, a práxis política é dotada de mediações que podem propiciar a construção do bom senso.

Por fim, Gramsci aponta, segundo Coutinho (2017, p.813), que a relação entre vontade coletiva e democracia é importante, pois a ausência de tal vontade leva a um despotismo burocrático. Relacionando isso com a conjuntura brasileira atual, seria a própria manutenção da pequena política em detrimento da luta social. Ou de certo modo, poderíamos articular este fenômeno à passividade política e atribuição das decisões ao poderes ou instituições republicanas meramente, como se elas por si mesmas resolvessem a vida em coletividade.

\footnotetext{
${ }^{24}$ Gramsci $(2011$, p.25) critica Croce, pois atribui a ideia de paixão política, a ausência de partido político, já que a paixão não pode ser organizada e permanente, uma vez que ela é uma ética e não uma moral política.
} 
Coutinho entende que a ausência de uma democracia real e a passividade da vontade coletiva leva a necessidade de um despotismo mais ou menos aberto a burocracia. Em contrapartida, vontade coletiva em Gramsci remonta a perspectiva da soberania (popular). É nessa perspectiva que os jovens atuaram. Ocupando a escola eles construíram uma democracia direta, no qual o poder de decisão era construído por eles em coletividade. Sendo assim está havendo uma reforma intelectual e moral, o que pode levantar a possibilidade de construção de outra hegemonia.

Bobbio (1986) elabora uma reflexão pertinente sobre o futuro da democracia e levanta desde o final do século XX a preocupação com os rumos desta. 0 filosofo italiano entendia que aprimorar a democracia, sobretudo no que diz respeito à capacidade da sociedade civil de participar mais da vida coletiva é necessário para ampliar a legitimidade desta.

Na ausência de viabilidade de implementar uma democracia direta na sociedade moderna contemporânea, desenvolver ferramentas de participação mais direta nas decisões políticas é uma alternativa a ser pensada e explorada.

Os discentes apresentam uma crítica contundente à democracia contemporânea, mas também reivindicam mais democracia no interior da escola, assim como mais espaço para à juventude construir sua identidade. Verificamos um duplo movimento de certa resistência à democracia moderna e reconhecimento da sua importância. Desta forma, a experiência de uma democracia direta se demonstrou significativa para a construção da representação da democracia como um valor universal, como aponta Coutinho (1984).

Uma dúvida que se impõe nesse horizonte de debate é se o um "moderno príncipe", que Gramsci considera tão crucial, vai surgir destas relações de classe. A priori, nitidamente, isto não está colocado nesse tipo de Novos Movimentos Sociais.

3. Sobre às demais categorias de conteúdo da investigação: 
As categorias a serem abordadas a seguir estão fortemente presentes no momento histórico atual, o que dificulta traçar uma análise mais gramsciana dos fenômenos. A partir deste espaço, no artigo, adotamos um tom mais descritivo, porém necessário para maturar o entendimento do objeto delimitado.

3.1. Debates sobre feminismo e protagonismo feminino nas atividades de liderança

Nas escolas visitadas foi perceptível que esta tendência estava consolidada. Em diversas situações, tínhamos jovens mulheres à frente das comissões de ocupação, assim como assumindo a tarefa de delegar atividades.

Por meio da ação destas militantes, problematizações sobre às relações de gênero eram feitas, assim como a indagação sobre o machismo advindo dos meninos engajados com o movimento.

Um fato interessante que pudemos observar foi a organização das tarefas, em uma das escolas, no Rio de Janeiro, no qual coube aos garotos os afazeres de culinária, de limpeza do espaço, como forma de ponderação sobre papéis históricos cumpridos por mulheres. Oficinas sobre gênero e feminismo foram uma tônica desta experiência. Em algumas situações, o apontamento da importância do debate sobre gênero nos currículos escolares foi sinalizado.

\subsection{Diversidade sexual e respeito às minorias}

Os estudantes acompanharam uma tendência global dos novos movimentos sociais e se dedicaram com veemência às pautas associadas às minorias, as mais presentes foram a questão étnico-racial e questões LGBT.

O combate sobre a LGBTfobia esteve presente desde as conversas de corredores, até na reflexão sobre o cotidiano de estudantes que estavam, em algum grau, ligados a causa.

A materialização destas ações se concretizou em postagens nas redes, realização de oficinas, ampliação da consciência sobre a temática etc. 


\subsection{Revisão dos currículos escolares}

As categorias descritas acima são pontos altamente motivadores para promoção de uma revisão do currículo escolar. É válido ressaltar que a identificação com o espaço público (que é uma dimensão fundamental da vontade coletiva construída nessas lutas) perpassa bastante pela contemplação das pautas identitárias destes jovens.

Em entrevistas, discentes diziam que era difícil seguir a trajetória escolar, uma vez que a escola não dialogava com o "tempo deles".

Um debate presente na ocasião era a proposta do Escola sem Partido, que tem seu teor uma mudança na abordagem curricular dos conteúdos da escola. Todavia, os eixos político-paradigmáticos de uma reformulação curricular dos militantes iam a sentido contrário às bandeiras do ESP.

\subsection{Autogestão}

Em todas as escolas visitadas, as experiências da autogestão foram aspectos basilares. A estrutura autogestionária era oriunda das assembleias, ou seja, o rompimento com modelos hierárquico de relações estava latente. A descentralização de atividades e a interatividade via redes foram significativas.

As escolas mantinham páginas nas redes, promovendo um canal de comunicação com a comunidade local, com a imprensa, com o poder público, com outras escolas etc. Experiências como assembleias interescolas, mobilizações simultâneas foram feitas também.

Entendemos que o cumprimento de tarefas promovia, constantemente o processo que Gramsci (1986) entenderia como a construção de intelectuais orgânicos, pois à medida que o afazer cotidiano era cumprido, seguido de uma mobilização coletiva, um movimento de passagem do senso comum ao bom senso se amalgamava. Existe aqui uma dialética da filosofia da práxis no qual a consciência político-filosófica está ligada a ação concreta, ou a força material das ideias. Um discente descreveu, em entrevista, que o 
responsabilizar-se com a escola, o ajudou a ter mais responsabilidade em outras dimensões da vida.

Muitos pais ajudaram também os filhos, o que para alguns discentes foi crucial para o prosseguimento na luta.

Recorrendo à literatura da teoria pedagógica, Pistrak (2000) considera a autogestão do trabalho pedagógico como uma categoria das mais importantes, numa experiência transformadora educacional, pois para ele este é fator incontornável de uma pedagogia socialmente engajada e transformadora.

3.5. Questionamento do modelo de gestão escolar atual e luta pela gestão democrática

A gestão democrática da educação é pauta presente desde a Constituição de 1988, perpassa pela LDB (1996) até o Plano Nacional de Educação (2014-2024). Paro (1998) entende que está bandeira apesar de imprescindível, ainda é algo longínquo na realidade brasileira. Como exemplo, temos a eleição de diretores de escolas, que ainda representa uma realidade exógena à maioria das nossas escolas. Alguns estados estão avançando nesse sentido, como o próprio Rio de Janeiro, que no mesmo ano das ocupações aprovou uma lei que assegura a eleição direta nas escolas.

Aplicamos 17 questionários, somente em cinco obtivemos respostas negativas quanto ao conhecimento dos discentes sobre o tema gestão democrática na escola. Contudo, não necessariamente, eles detinham conhecimentos sobre a política educacional brasileira e o marco legal vigente.

Findadas as ocupações, notícias veiculadas nas redes sociais revelaram que duas escolas visitadas, fizeram eleição direta nas suas unidades.

\section{Considerações finais}

"Excelente a forma radical que os estudantes se manifestaram através da ocupação e somente assim que nós somos ouvidos" 
"Mudou muito a forma como via a escola e a política. Passei a ter uma relação de mais carinho e admiração pela escola e ser mais politizada"

(Daiane)

As ocupações estudantis aqui discutidas demonstraram se assemelhar à linha dos Novos Movimentos Sociais contemporâneos e impuseram desafios significativos que tentamos explorar sua natureza. As reflexões que elaboramos visaram demonstrar nossa preocupação em entender esse fenômeno e assim, foi possível notar a centralidade do denso legado de Antônio Gramsci para esta análise.

Concluímos que há uma insatisfação elevada dos jovens estudantes sobre a gestão democrática das escolas (no plano da mediação particular), assim como sobre os rumos da educação como um todo no estado do Rio de Janeiro e do Brasil (mediação intermediaria).

A fala da estudante Daiane retrata o grau de indignação geral visto na atividade de campo e na pesquisa como um todo. Este sentimento permeou a vontade coletiva dos ocupantes. Os desdobramentos disso foram notados em como as ocupações mobilizaram a opinião pública. Muitos foram os solidários à causa dos estudantes. Verificamos muitos pais, as comunidades locais, em geral, apoiando as ocupações, doando alimentos, fazendo oficinas etc. Contudo, não foi uma unanimidade, pois não foram poucas as vezes que os estudantes foram acusados de "rebeldes sem causa" e as ocupações taxadas como descabidas e outras críticas. Um movimento importante surgiu em praticamente todas as escolas ocupadas, o "Desocupa”, no qual alunos das escolas, pais etc. reivindicavam o fim das ocupações e a volta as aulas. Esta questão merece estudos futuros.

Em algumas falas de entrevistados, ouvimos dos discentes que eles estavam preocupados não só com a conclusão do ano letivo de 2016, mas com mudanças no país e que isso começa pela luta por uma educação melhor para eles e para as gerações futuras.

Verificamos, por meio das representações sociais dos estudantes fluminenses, que as experiências políticas vividas foram significativas para 
estes sujeitos, na perspectiva da construção da identidade coletiva e da participação política.

Foi possível notar que a percepção dos estudantes sobre às categorias de conteúdo elencadas foram de suma relevância para auxiliar na construção de uma dimensão filosófica que Gramsci denominaria de um movimento da práxis de passagem do senso comum ao bom senso sobre temas da luta coletiva. Verificamos princípios (como a não distinção entre trabalho manual e intelectual; uma formação filosófica humanista; formação política dos filhos da classe trabalhadora; além da materialidade da democracia como um valor) que o autor desenvolve sobre a construção de uma Escola Unitária.

A investigação levou a elaboração de novas indagações, como entender os desdobramentos dessa experiência política no futuro desses jovens. Especificamente, é interessante entender às representações sociais destes sobre a política na atualidade. Ou até mesmo entender o grau de reflexão que eles têm nesse momento sobre vários temas, como o empoderamento feminino, o respeito à diversidade sexual e outros, que remetem aos debates travados nas ocupações.

Outra indagação de fundo é compreender se a vontade coletiva mobilizada em 2016 vem ganhando força material das ideias para a construção de perspectivas democráticas mais afinadas com os novos tempos e que contemplem às pautas de reivindicação da juventude brasileira.

\section{Referências}

ALVES, Giovanni. Ocupar Wall Street... e depois? In: HARVEY, David (Et al.) Ocuppy. Movimentos de Protestos que tomaram as ruas. São Paulo: Boitempo: Carta Maior. 2012.

BOBBIO, Norberto. 0 futuro da democracia (uma defesa das regras do jogo). Rio de Janeiro, Paz e Terra, 1986.

BOURDIEU, Pierre. 0 Poder simbólico. 15. ed. Rio de Janeiro: Bertrand Brasil. 2011.

BOURDIEU, Pierre. Poder, derecho y clases sociales. Bilbao, Desclée de Brouwer, 2001.

BRASIL. Medida Provisória no 746, de 22 de setembro de 2016. 
BRASIL. Lei № 13.005, Plano Nacional de Educação - PNE , de 25 de junho de 2014.

BRASIL. Emenda Constitucional no 95/2016, de 15 de dezembro de 2016.

BRASIL. Lei 13.415/2017, de 16 de fevereiro de 2017.

BRASIL. Lei 9.394/1996. Lei de Diretrizes e Bases da Educação Nacional, de 23 de dezembro de 1996.

BRASIL. Projeto de Lei 867/14, de 23 de março de 2015.

BRASIL. Proposta de Emenda Constitucional 55/2016, de 27 de maio de 2015.

BRASIL. Proposta de Emenda Constitucional 37, 08 de junho de 2011.

BUCI-GLUCKSMANN, Christinne. Gramsci e o Estado. 2. ed. Rio de Janeiro: Paz e Terra, 1990.

CAMPOS, Antonia; MEDEIROS, Jonas; RIBEIRO, Marcio. Escolas de Luta. Coleção Baderna. São Paulo: Veneta, 2016.

CARNEIRO, Henrique Soares. Apresentação: rebeliões e ocupações de 2011. In: HARVEY, David (Et al.) Ocuppy. Movimentos de Protestos que tomaram as ruas. São Paulo: Boitempo/ Carta Maior, 2012.

CASTELLS, Manuel. A sociedade em rede. A era da informação: economia, sociedade e cultura. V. I, 6. ed., São Paulo: Paz e Terra, 2002.

COUTINHO, Carlos Nelson. 0 conceito de vontade coletiva em Gramsci. Rev. Katál. Florianópolis v. 12 n. 1 p. 32-40 jan./jun. 2009.

COUTINHO, Carlos Nelson. A democracia como valor universal e outros ensaios. 2. ed. Rio de Janeiro: Salamandra, 1984.

COUTINHO, Carlos Nelson. Vontade Coletiva. In: LIGUORI, Guido; VOZA, Pasquale. (Orgs.) Dicionário gramsciano (1926-1937). 1 ed. São Paulo: Boitempo, 2017.

EL PAIS. (2016) PEC 241: Com quase 1.000 escolas ocupadas no país, ato de estudantes chega a SP. Disponível em:

http://brasil.elpais.com/brasil/2016/10/24/politica/1477327658 698523 html Acesso em 20 de dezembro de 2016

FLACH, Simone Fátima. Políticas Públicas, Estado e Educação: notas a partir dos escritos de Gramsci. Movimento Revista de Educação. Ano 3, no. 5, 2016. 
FLACH, Simone Fátima; SCHLESENER, Anita Helena. Análise de conjuntura sobre a ocupação de escolas no Paraná a partir do pensamento de Antonio Gramsci. ETD- Educação Temática Digital Campinas, SP v.19 n.1 p. 165186 jan./mar. 2017.

FONTES, Virgínia. Sociedade Civil (Verbete). Dicionário da Educação Profissional em Saúde. Disponível em:

http://www.epsjv.fiocruz.br/dicionario/verbetes/socciv.html . Acesso em: 30 de março de 2017.

FREITAS, Luiz Carlos de. Os reformadores empresariais da educação: da desmoralização do magistério à destruição do sistema público de educação. Educ. Soc., Campinas, v. 33, n. 119, p. 379-404, abr.-jun. 2012.

GIDDENS, Anthony. As consequências da modernidade. São Paulo: Editora UNESP, 1991.

GLOBO. (2016) Ocupação de escolas e universidades chega a 19 estados. Bom dia Brasil: Edição do dia 26/10/2016. Disponível em: http://g1.globo.com/bom-dia-brasil/noticia/2016/10/ocupacao-deescolas-e-universidades-chega-19-estados.html Acesso em 20 de dezembro de 2016.

GOHN, Maria da Glória. Teorias dos Movimentos Sociais: Paradigmas Clássicos e Contemporâneos. 1. ed. SÃO PAULO: Edições LOYOLA, 1997.

GOHN, Maria da Glória. Manifestações e protestos no Brasil: correntes e contracorrentes na atualidade. São Paulo: Cortez, 2017.

GRAMSCI, Antônio. Cadernos do Cárcere, v. 1. Introdução ao Estudo da Filosofia a filosofia de Benedetto Croce. 3. ed. Rio de Janeiro: Civilização Brasileira, 2004.

GRAMSCI, Antônio. Cadernos do Cárcere, v. 3. Maquiavel, Notas sobre o Estado e a política. Rio de Janeiro: Civilização Brasileira, 4⿳a Janeiro, 2011.

GRAMSCI, Antônio. Cadernos do Cárcere, v. 6. Literatura. Folclore. Gramática. Apêndices: variantes e índices. Rio de Janeiro: Civilização Brasileira, 3를. Ed. Rio de Janeiro, 2014.

HARVEY, David. Condição Pós-moderna. São Paulo: Loyola, 2009.

KUENZER, Acácia Zeneida. Desafios Teórico-metodológicos da relação trabalho-educação e o papel social da escola. In: FRIGOTTO, Gaudêncio (org.). Educação e crise do trabalho: perspectivas de final de século. Petrópolis: Vozes, 1998.

MARX, Karl. Contribuição à crítica da economia Política. 2 ed. São Paulo, Expressão Popular, 2008. 
MORAES, Carmen Sylvia Vidigal; XIMENES, Salomão Barros. Políticas educacionais e a resistência estudantil. Revista Educação e

Sociedade, vol.37, n. 137. Campinas. Oct./Dec. 2016. Disponível em: http://dx.doi.org/10.1590/es0101-73302016171219

NOGUEIRA, Marco Aurélio. As ruas e a democracia: ensaios sobre o Brasil contemporâneo. Brasília: Fundação Astrogildo Pereira (FAP); Rio de Janeiro: contraponto, 2013.

PARO, Vitor Henrique. Diretor Escolar: educador ou gerente? São Paulo: Cortez, 2016.

PARO, Vitor Henrique. A gestão da educação ante as exigências de qualidade e produtividade da escola pública. In: SILVA, Luiz Heron da (org.) A escola cidadã no contexto da globalização. Petrópolis, Vozes, 1998.

PIKETTY, Thomas. 0 Capital no século XXI. 1 ed. Rio de Janeiro: Intrínseca, 2014.

PISTRAK, Moisey. Fundamentos da escola do trabalho. São Paulo. Expressão Popular, 2000.

REIS, Cláudio Araújo. Vontade geral e decisão coletiva em Rousseau. Trans/Form/Ação, vol.33 no.2 Marília, 2010. http://www.scielo.br/pdf/trans/v33n2/v33n2a03.pdf

RIO DE JANEIRO. Decreto 45.692/16, de 17 de junho de 2016.

ROUSSEAU, Jean-Jacques. Do Contrato Social. Coleção A Obra Prima de Cada Autor. São Paulo - SP: Editora Martin Claret, 2003.

SANTOS, Boaventura Sousa. (2005) Os novos movimentos sociais. In: LEHER, Roberto; SETÚBAL, Mariana. (Orgs.). Pensamento crítico e movimentos sociais: diálogos para uma nova práxis. São Paulo: Cortez, 2005.

SEPE (Sindicato Estadual dos Profissionais de Educação do RJ). Pezão não paga 13 salário e propõe que a categoria se endivide. 18 de dezembro de 2015. Disponível em:

http://www.seperj.org.br/ver noticia.php?cod noticia=6643. Acessado em 25 de março de 2017.

SAVIANI, Dermeval. Sistema Nacional de Educação e Plano Nacional de Educação: significado, controvérsias e perspectivas. Campinas, SP: Autores Associados, 2014.

SEPE (Sindicato Estadual dos Profissionais de Educação do RJ). Pezão quer aumentar para 14\% a contribuição previdenciária - dia 3 os servidores darão a resposta. 6 de janeiro de 2016a. Disponível em: 
http://www.seperj.org.br/ver noticia.php?cod noticia=6674. Acessado em 25 de março de 2017.

SEPE (Sindicato Estadual dos Profissionais de Educação do RJ). 10 BOLETIM DA GREVE DO ESTADO. 02 de março de 2016b. Disponível em: http://www.seperj.org.br/ver noticia.php?cod noticia=6728. Acessado em 25 de março de 2017.

SEPE (Sindicato Estadual dos Profissionais de Educação do RJ). NOTA DO SEPE SOBRE O ATRASO NOS SALÁRIOS DOS SERVIDORES ESTADUAIS. 09 de março de 2016c. Disponível

em:http://www.seperj.org.br/ver noticia.php?cod noticia=6753. Acessado em 25 de março de 2017.

TRASPADINI, Roberta. A dialética da dependência contemporânea: a educação como mercadoria. REBELA, v.8, n.1. jan./abr. 2018.

UBES (União Brasileira de Estudantes Secundaristas). Estudantes se mobilizam contra desmonte na educação do Rio de Janeiro. 1 de março de 2016. Disponível em: http://ubes.org.br/2016/estudantes-semobilizam-contra-desmonte-na-educacao-do-rio-de-janeiro/ Acessado em: 20 de março de 2017.

WOOD, Ellen. Democracia contra o capitalismo: a renovação do materialismo histórico. São Paulo: Boitempo, 2011. 